Short Review

\title{
Mindfulness in Well-Being, Cognition and Learning: Benefits on Higher Education and Health-Care Professions
}

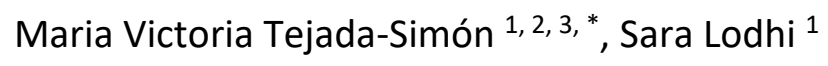

1. Department of Pharmacological and Pharmaceutical Sciences, College of Pharmacy, University of Houston, Houston, Texas, USA; E-Mails: mvtejada@central.uh.edu; saralodhi15@gmail.com

2. Biology of Behavior institute, BoBi, University of Houston, Houston, Texas, USA

3. Department of Biology, College of Natural Sciences, University of Houston, Houston, Texas, USA

* Correspondence: Maria Victoria Tejada-Simón; E-Mail: mvtejada@central.uh.edu

Academic Editor: Peta Stapleton

Special Issue: Mind-Body Approaches that are Revolutionizing the Health Field

OBM Integrative and Complementary Medicine

2022, volume 7 , issue 1

doi:10.21926/obm.icm.2201009
Received: November 14, 2021

Accepted: March 01, 2022

Published: March 04, 2022

\begin{abstract}
Mindfulness is a form of meditation that can be defined as one's ability to be present to the surroundings and environment, and not overreact to what is happening around us. With the recent pandemic still affecting the world, more studies have recently become known describing the suitability of mindfulness to prevent and manage mental health. This fact alone offers grounds for mindfulness practices to be added to any stressful environment, including Institutions of higher education and the workforce. Even more, mindfulness practices have a strong link to brain function, increasing cognitive ability, memory, and emotional regulators. The objective of mindfulness-based practices is to experience cognitive flexibility and attentional focus, essential traits for students and health-care professionals in today's world. As a College of Pharmacy, training future healthcare workers, we wanted to decide whether mindfulness practices might be of benefit to be included in the curriculum. Herein we performed a selective literature review to determine how mindfulness affect human cognition and learning. We observed that, compared to non-meditators, meditators are more likely to
\end{abstract}

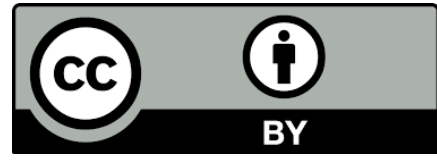

(C) 2022 by the author. This is an open access article distributed under the conditions of the Creative Commons by Attribution License, which permits unrestricted use, distribution, and reproduction in any medium or format, provided the original work is correctly cited. 
experience less mental, emotional, and physical symptoms associated with stress, burnout, or feelings of hopelessness. Several studies discuss the improvements that mindfulness-based meditation has on cognitive flexibility and attentional functions. We widen our search to reveal the impact that mindfulness-based meditation has in the stress observed in education, students and healthcare professionals. Higher education and health professionals are more likely to experience severe stress and suffer from enervation. We concluded that, in our line of work, those pursuing higher education and health professional degrees would benefit from practicing mindfulness. Incorporating mindfulness-based meditation can help alleviate these symptoms and improve not only the quality of life and learning, but also the patient-doctor interaction.

\section{Keywords}

Mindfulness; healthcare professionals; pharmacists; cognition; learning

\section{Introduction}

\subsection{What is Mindfulness?}

As a form of meditation, mindfulness is the capability to be fully aware, present to our surroundings and environment, by paying attention on purpose, nonjudgmentally, without overreacting to what is happening around us [1]. Every individual has the ability to practice mindfulness; it is just a matter of training and being consistent with a daily practice. Mindfulness is not one thing, but a collection of many things, such as seated and moving meditation, long and deep breaths to pause life at times, and merging movement with meditation (yoga, tai-chi, and other various types of active movement; [1, 2]). Reducing stress, increasing performance, and gaining insight to one's self and to others around us are just a few ways that mindfulness can upgrade someone's life for the better. Mindfulness practice allows a person to become less judgmental and approach life in a more calm and peaceful manner. It is a way of living that suspends stress and increases the satisfaction and happiness of life. Being more mindful is a tool that allows us to experience and relate to world events, while being less reactive and more understanding. Being less reactive is a skill that many people do not take the time to work on. Life can sometimes be described as being on 'autopilot,' since we can become unaware of the sights, sounds, and smells around us. When our minds are 'switched off', we tend to ruminate in the past and stress about the future. Acknowledging and staying in the present is a key to being more mindful [3].

\subsection{Historical Perspective of Mindfulness}

The foundation for living a more mindful life originates from Buddhism and its philosophy. Some argue that Buddha's five methods of dealing with difficult thoughts (think positive, know what hurts, distract yourself, question your thinking, and push it away) are actually examples of what we can call early "Buddhist cognitive behavioral therapy" [4]. Mindfulness is originally a 2500 year-old Buddhist practice, viewed as a style of meditation with ethical and moral dimensions [5]. Mindfulness practices popular in the West have stemmed, among others, from Vipassana culture 
(meaning "insight"), in conjunction with Zen and Tibetan Buddhism traditions [6]. However, contemporary mindfulness has now emerged as a secular and clinical application to treat psychological distress, and not necessarily linked to a religious movement, but better perceived as a science of the mind [7]. Thus, the origins of mindfulness as a Buddhist practice are not connected to what we now know as mindfulness-based interventions. This is a general concern from Buddhist scholars who feel that mindfulness still needs to be embedded in the complete Buddhist program [8].

In the 1970s, Westerners traveled to India, Thailand, and other Asian countries to seek mindfulness practices and brought back the concept of 'a mindfulness movement' to North America $[9,10]$. They interpreted the Buddhist notions learned and molded it to fit into the modern, western life. Nowadays, mindfulness is a word used by contemporary neuroscientists as well as laypersons to describe a practice related to modern therapeutic outcomes, with no exposure to Buddhism [11]. There are several therapeutic mindfulness-based interventions [11]. Pioneers like Jon-Kabat Zinn, created Mindfulness-Based Stress Reduction (MBSR) practices, which were taken to research, aiming to help the medical field figure out natural alternatives for patients living with mental or physical disorders, and making these practices highly accessible [12]. Other mindfulness-based interventions are Dialectical Behavior Therapy (DBT), Mindfulness-Based Cognitive Therapy (MBCT) which teaches patients to observe their thoughts, and Acceptance and Commitment Therapy (ACT), which teaches to accept unpleasant sensations rather than controlling them [13]. Mindfulness is a part of the practice of meditation, and as such, it involves mental training to increase the ability to sustain attention.

Because mindfulness is considered a meditation style, many meditation practices are taught with the intention to just cultivate mindfulness (Table 1). The origins of meditation derive from the Vedic and yogic tradition from India, and it is also intertwined with Hinduism [14]. As time went on, different forms of meditation practices developed in Buddhism and Taoism. World-renowned figures such as Deepak Chopra and Gurudev Sri Sri Ravi Shankar brought these practices to the West. Traditionally, the intent of meditation is to achieve ultimate liberation, also known as 'Nirvana', to live in a peaceful state of mind. Meditation is the ability to transcend the mind, while staying in the present state [14]. A prominent figure in the spiritual and meditation community, Gurudev Sri Sri Ravi Shankar, defines meditation as: 
Table 1 Meditation \& mindfulness-based practices. Adapted from Cabrera-Caban, 2016 [16] \& Harris, 2007 [17].

\begin{tabular}{|c|c|}
\hline Meditation-based practices & Examples on type of exercises \\
\hline Concentration & Breath-focused meditation \\
\hline \multirow[t]{4}{*}{ (word, thought, sensation, image) } & Relaxation \\
\hline & Mantra repetition \\
\hline & Mandala \\
\hline & Transcendental meditation \\
\hline Transcendental-based & Mantra \\
\hline \multirow[t]{2}{*}{ Emptying-based } & Centering prayer \\
\hline & Searching inner voice/inner light \\
\hline \multirow[t]{3}{*}{ Positive emotions-based } & Compassion and loving kindness \\
\hline & (Buddhist metta or tonglen practices) \\
\hline & Gratitude \\
\hline \multirow[t]{4}{*}{ Movement-based } & Yoga \\
\hline & Tai Chi \\
\hline & Qi gong \\
\hline & Sufi dancing \\
\hline Mindfulness-based practices & Examples on type of exercises \\
\hline Mindfulness-based stress reduction & Body scan and yoga \\
\hline \multirow[t]{5}{*}{ (MBSR) } & Mindful stretching \\
\hline & Focused breathing \\
\hline & Mindful eating \\
\hline & Walking meditation \\
\hline & Loving kindness sessions \\
\hline Mindfulness-based cognitive & Journaling \\
\hline \multirow[t]{2}{*}{ behavioral therapy (MBCT) } & Challenge thoughts \\
\hline & Introspective exposure \\
\hline \multirow[t]{3}{*}{ Dialectic behavior therapy (DBT) } & Observe \\
\hline & Describe \\
\hline & Non-judgmental stance \\
\hline \multirow[t]{3}{*}{ Acceptance commitment therapy (ACT) } & Contact with present moment \\
\hline & Acceptance \\
\hline & Defusion \\
\hline
\end{tabular}


"the delicate and effortless art of doing nothing. It is the skill to take a deep rest while being conscious and alert. Beyond all the chatter and noise in our mind, there is a silent, peaceful, blissful, beautiful space that exists in all of us, a place that is intact and unbroken. Turning our attention to this silent chamber is meditation. This silence cleanses the mind, giving it a much-needed rest, and makes room for better perceptions and new ways of looking at life and its challenges."

There is a category of meditative practices called "mindfulness meditation," which help the practitioner to live and act with mindfulness [15]. Mindfulness meditation also stems from Buddhist traditions, but since the 1990s it has also been applied to mental and physical health conditions, receiving a lot of attention in clinical psychology [15]. One does not have to meditate to be mindful.

Today, mindfulness and meditation are used interchangeably trying to mean the same thing. These concepts are mirror-like of each other, with mindfulness supporting and elevating meditation, and meditation promoting and increasing mindfulness. It is true they both refer to calming one's state of mind, but they both have fixed definitions that differ from each other. The Merriam dictionary states that 'Mindfulness' is the basic aptitude of a person to be fully present, aware of where they are and what they are doing, and avoid being overly reactive or overwhelmed by what is going on around them. While 'Meditation' refers to the practice of engaging in contemplation or reflection, as a mental exercise, with the purpose of reaching a higher spiritual awareness. Mindfulness can be applied to any situation through your day. Meditation is usually practiced for a specific amount of time. To achieve mindfulness is to increase awareness of one's own thoughts and emotions. The idea of mindfulness is to rewire the inner mechanisms of our mental, emotional, and physical well-being for the better [14]. The focus of meditation is to let go of the burdens or heavy feelings a person is dealing with and to simply relax into your natural self. The idea of 'letting go' is to empower ourselves to live in a calm and blissful state of mind. Thus, there are notable differences between practicing mindfulness and meditation (Table 2).

Table 2 Comparison of secular mindfulness and meditation.

\begin{tabular}{lll}
\hline & MINDFULNESS & MEDITATION \\
\hline Process & Being aware of the mind & Transcending the mind \\
State of Mind & Active & No mind \\
Level of ease & Requires some effort & Effortless \\
Thoughts & Watchful of thoughts & Letting go of thoughts \\
Sense of time & Fully aware & Loss of time sense \\
Benefits & Many according to research & Many according to research \\
\hline
\end{tabular}

It is important to note that mindfulness is not a replacement for meditation; they each serve their own purpose. After meditation progressed and became more refined in the West, it has become a broader, loose term of reaching spiritual transcendence, which is the idea of increasing awareness and concentration, acknowledging the mind, and reaching optimum consciousness. There are numerous ways to achieve this heightened level of concentration, such as practicing compassion, love, patience, and mindfulness. Thus, mindfulness is a type of meditation, alongside mantra, tantra, silence, and breathing [14].

The process of mindfulness is to become more aware of the mind. The state of mind for mindfulness is to keep an individual active, keeping you on the surface of the mind [18]. Meditation 
is to have 'no-mind' and take you to your core of being [14]. The level of ease of mindfulness does require some effort to stay focused and alert, while meditation is supposed to be effortless. Mindfulness helps one stay aware of their thought process, to diminish negative thoughts, while meditation allows for the release of thoughts. In mindfulness, an individual is fully aware of their sense of time and surroundings, while meditation allows one to lose sense of time. When practicing together, mindfulness and meditation have many benefits (Table 2). It is easier to practice mindfulness than meditation. Effort is required to make sure the mind does not drift too far out, while keeping full awareness in your thoughts to stay focused and alert. Meditation requires no effort since the goal is to turn inwards and become thoughtless. Meditation is not supposed to be forced but to come naturally. Meditation allows for letting go of the thoughts weighing you down and ultimately having a blank, yet blissful state of mind.

\section{Mindfulness and the Brain}

By being mindful, we are having an alert and active mind, while ensuring the mind is not drifting away from the present moment. If the mind starts to wander, you actively bring it back to the activity you are doing: breathing, walking, talking, etc. [14]. Consequently, mindfulness must have a strong link to the brain, as it occurs on the surface level of the brain, the waking state of consciousness, and does not promote transcendence [14]. Transcending is different from mindfulness, and its results in the brain have been confirmed by electroencephalogram (EEG) brainwave research, having more profound benefits than the other three states (sleeping, dreaming and wakefulness, [14]).

Mindfulness related research has increased exponentially since the 1900's, searching whether or not mindfulness might contribute to a person's well-being. Benefits found include improved psychological, cognitive, medical, and interpersonal results. Individuals suffering from depression, anxiety, chronic pain, stress, and insomnia have seen small but consistent symptom improvement from mindfulness-based interventions, alongside cognitive-behavioral approaches [19, 20]. Mindfulness has also enhanced the quality of life for those suffering with chronic and dreadful illnesses, such as cancer. For example, cancer patients have seen improvements in mood, stress, and fatigue when dealing with physical and mental symptoms [21, 22]. Other research has point out to benefits for patients suffering from diabetes, fibromyalgia, cardiovascular disease, HIV/AIDS and other disorders $[23,24]$, which are able to cope better with their illness.

Consistently and continuously working on attention and awareness can lead to cognitive benefits. Practicing mindfulness can lessen unproductive cognitive rumination, while diminishing negativity bias such as distressing thoughts, emotions, and experiences [25-28].

Even though the research of mindfulness improving physical illness is still controversial, there are reports that this practice might reduce stress and other mental disorders [29-31]. Better physical health and biological feedback are associated with mindfulness, leading to reduced levels of cortisol and increased immunological responses [32]. Additionally, mindfulness appears to increase the longevity of cells in the human body by increasing the levels of the enzyme telomerase, an enzyme that helps prolong the life of cells $[33,34]$. 


\subsection{Mindfulness in Learning and Cognition}

Practicing mindfulness has the power to bring positive physiological changes to the brain. Neuroscientists have found that mindfulness and meditation lead to a healthy brain function, by increasing cognitive ability, memory, and emotional regulators [35]. The thickness of the left hippocampus and the posterior cingulate increases through mindfulness meditation daily practice, by augmenting the density of gray matter. The pons, assisting in functions such as sleeping, facial expressions, sensory input, and physical functioning, is also strengthened, while the amygdala shrinks. This is actually a positive effect, since the amygdala is responsible for feelings of anxiety, fear and stress $[35,36]$. Strengthening areas in charge of self-awareness, empathy, information process and regular daily functions avoids the mind to wander, and trains the brain to remain in the present moment. All of this is possible through 'rewiring' the brain to become more efficient. Mindfulness-based training has been described as a fundamental process for improving problem solving and attention, which account for higher order cognitive abilities. Children go through many changes in their prefrontal cortex, as they start to mature towards puberty. Practicing mindfulness might aid in the process as it might be considered another variant of attention (a cognitive sensation in itself), which is of paramount interest for K-12 and higher education.

Research involving adolescents aiming to investigate a correlation between mindfulness and cognition found that there is a positive association between mindfulness practice and behavioral/cognitive performance. Students using mindfulness-based training showed better cognitive performance, as well as improvement in emotional handling, stress, and resilience [37]. Moreover, to test how mindfulness meditation intertwines with working memory, several studies using different methodology concluded that mindful-based meditation improved working memory capacity [38-40]. Additionally, multiple studies agree that mindfulness meditation can aid in cognitive inhibition [41-43], boosting problem solving [44-46] and creativity [47].

Another research study involving fifth graders aimed to report the effects of mindfulness-based training in that school population. Children were randomly assigned to either a mindfulness intervention group (with two subgroups: sitting meditation and body scan) or a control group that had no intervention. The study used verbal self- instruction and principles from cognitive behavior therapy. The intervention for this group was based on advanced exercises from an adult's version, by replacing with easier exercises for fifth graders [48]. The intervention group improved sustained attention, cognitive flexibility, cognitive inhibition, and data driven processing. They also performed better in increased body awareness and controlling emotions [49]. The study tried to determine whether there is a gender effect within the mindfulness practice group, determining that girls performed marginally better than boys did. While, no theories about the differences observed by genders could be derived, it should be noted that there was no differential training between girls and boys [49], so no benefit could come through training. These experiments correlate with findings found with adults and indicate that mindfulness-based training can improve cognitive abilities in children and adults. However, the sample for most of these studies is small, thus, further studies would be necessary, with larger number of subjects to replicate and confirm the results. Nevertheless, since children tend to make more impulsive and emotional decisions, making emotions compete with attention via the cognitive process, these studies already point to the possible benefit of mindfulness training in strengthening the self-regulatory capacity in children, showing the potential benefits on cognition and learning. 


\subsection{Mindfulness in Affective Disorders and Physical Illness}

From 2015 to 2017, 16.1 million Americans suffered from depression, with two-thirds of Americans dealing with high-levels of stress (American Psychological Association,. [50]). For many of these people, talk-therapy and antidepressants were not successful. In addition, the American Heart Association reported increasing levels of high blood pressure from 72 million to 103 million people in the last few years [50]. To find a new treatment, researchers turned to mindful-based meditation [51]. This type of studies have grown in the last years, moving from 11 to 216 by 2018. In a small eight-week study, participants practiced mindful-based meditation. The results showed a significant decrease in 172 genes involved in inflammation, circadian rhythms, and glucose metabolism, which influence blood pressure, concluding that a simple intervention designed at emptying the mind of the constant barrage of intrusive thoughts could translate in major physical benefits [52].

Due to increased stress, mindful-based meditations can aid patients in lowering their anxiety and living a calmer life. However, some studies reported a moderately positive effect, meaning that although mindful-based meditation had positive effects in some patients, it is still not a guaranteed replacement for antidepressants, antihypertensive medication and/or individualized cognitive behavioral therapy. Mindfulness-based meditation could be used alongside medication to help lower stress and control physical illnesses [52]. Additionally, mindfulness has shown benefits in other patients with mental and physical conditions such as anxiety [53], depression, irritable bowel syndrome, and post-traumatic stress disorder [52].

\subsection{Mindfulness Interventions in Higher Education and Healthcare Professionals}

Stress can hinder a student's academic success and can create mental and emotional fatigue. College students are more likely to be stressed, have negative thoughts, and face distractions. It is important to find alternative practices to reduce these problems in higher education.

\subsubsection{Undergraduate Students}

There are many advantages to incorporating mindfulness meditation for higher education students. Focusing on the mental health of the students, a meta-analysis investigated how mindfulbased meditation can aid a student undergoing academic stress. The objective was to observe whether students experienced less stress, anxiety, depression, as well as balanced regulation of emotions and better psychological states. Aside from psychological benefits, mindfulness meditation helped enhance a student's creativity, empathetic responses, and self-compassion [54]. This study proved that a student's well-being and academic success could increase when mindfulbased meditation is practiced.

Another study measured whether cognitive-behavioral stress management could benefit a student's cognition yielding better mental health and learning. The students were measured pre and post intervention to see the difference in their academic success. Those who received the intervention had an increase in functionality of cognition, increase in motivation, and better accomplishments of academic performance, indicating that mindful-based meditation can improve cognition, creating more motivation for a student to get their work done, while being less stressed [55]. A study conducted by Jain et al. [56] looked at a mindful-based meditation versus a somatic 
relaxation-training program for one month. Both interventions interacted with thoughts of distress, euphoric states, rumination, distraction, and spirituality, yielding notable decreased distress and increased positive state of mind, compared to the control group [56]. Interestingly, the mindfulbased meditation group had a larger effect for positive states of mind and a decrease in negative self-talk than the somatic relaxation group. Nevertheless, both meditation and somatic relaxation helped the students, but mindful-based meditation was more beneficial in reducing distress and increasing self-positivity.

\subsubsection{Graduate Students}

Those pursuing higher education and health-related professions will most likely face burnout eventually. Graduate students are more likely to face mental stress during their tenure and afterwards searching for new jobs. Continually being anxious and stressed can lead to detrimental health consequences [16]. Five studies, sampling more than 4,000 graduate students, collectively found that graduate students face a multitude of stressors and strains. Those include high academic workload, challenging demands, finances, working while still in school, time management, work/school life balance, loneliness, rivalries and conflicts arising from their particular field of research [57-61].

A study by Shure et al. [62] examined the mental state of graduate students in the fields of psycho-therapy, counseling, or behavioral medicine, and the effect of introducing mindful-based approaches. This four-year qualitative study involved a 15-week semester of introducing hatha yoga, meditation, and qigong to see the influences on the graduate student's mental and physical health. The students had to perform their mindful-based practice every week and document their findings by the end of the semester indicating their physical, mental, emotional, and spiritual health. They reported to be able to handle stress better than at the beginning of the intervention, as well as having more clarity of thought, feeling more compassionate and empathetic [62]. More recently, the effects of mindfulness-based meditation were studied in a smaller group of college students. While students who practiced mindful-based meditation enjoyed the daily time for the exercise and reported decreased stress, there was not statistical significance compared to pre-intervention scores [63]. Nevertheless, after the study was completed, the students committed to incorporate more mindful-based approaches into their daily routine and suggested that the institution should offer more mindful-based approaches on campus, to benefit more students.

Some activities that graduate students report to deal with stress is by spending time with friends and family, eating, watching TV, exercising, or sleeping [16]. Meditation does not appear to be an established technique for managing stress. Thus, publicizing these type of results described above might encourage more graduate students to seek mindful-based approaches. In fact, and because mindfulness is becoming more known, about $42 \%$ of graduate students show curiosity towards trying mindful-meditation, while $44 \%$ indicate they would participate in this type of practice if offered by their University [61].

\subsubsection{Pharmacy Students}

Pharmacy students face higher levels of stress than the average population due to their rigorous program and increased workload $[64,65]$. The stress a pharmacy student faces while in school might even remain after becoming a pharmacist. This is also the case for other professional students, as 
the demands and challenges are alike [66-68]. Stress can impede academic performance and lead to depression and burnout, affecting negatively a student's well-being. This is a cause of concern when in the health professions, because increased stress leads to poor-decision making skills and can compromise patient safety by medication dosing errors. More than half of practicing pharmacists have reported that they deal with high levels of stress and work overload [64], being more likely to resign from their job than physicians. Thus, there is a curricular interest on mindfulness-based interventions to reduce stress associated with professional pharmacy as well as clinical practice.

In an interesting study by O'Driscoll et al. [69], five pharmacy schools in Ireland were sampled by recruiting students from all years. Five themed focus groups were created: (1) so much to do, so little time; (2) the role of the lecturer; (3) we're smart people, we want to do well; (4) learning by doing, and (5) mindfulness as a coping tool. The first group, "so much to do, so little time", worked on the heavy workload that pharmacy students have on a daily basis. Some students felt overwhelmed and had trouble multitasking, while meeting their deadlines. The pharmacy students were so focused on school; they had no life outside of school, working over weekends, with no social life [69]. The second intervention, "the role of the lecturer", reflected on how students do not feel their professors are accessible. The students felt no support coming from the instructors and thus affected their performance. The third theme, "We're smart people, we want to do well", discussed the desire the students have to perform well and stay ahead in class, avoiding low grades or failing, just not to fall behind their peers. The students fear failure, increasing their stress levels and impeding performance. Pharmacy students want to become great providers, and know their patients will depend on their academic success to make smart choices when it comes to medications and dosing. The fourth group, "learning by doing", appreciated the hands-on concept they got from pharmacy school and felt it gave them the skills for proper development. The fifth theme, "mindfulness as a coping tool", was incorporated to relieve the stress from the other four themes. Pharmacy students understood the benefits that a mindfulness program can have on future health professionals and their patients. Mindfulness was seen as stress prevention versus unrestrained stress. A majority of the participants knew what mindfulness was but still held some common misconceptions about it. Mindfulness training was incorporated in a weekly, online interactive course. The course involved reflection from learning mindfulness-based techniques for stress management and wellness, resulting in a relieve of stress and burden for the pharmacy students involved [69]. One initial limitation was to figure out the appropriate mindfulness practice time and length, as realistically the students could not commit too much time to the practice. The results were very positive and by the end of the study, they advocated for mindfulness-based training to be a part of the pharmacy curriculum [69].

Naturally, not all pharmacy schools were represented in this study and the results may differ in different pharmacy program from other countries. However, this study does support the claim that (1) pharmacy students are stressed out and may be suffering silently; and (2) introducing a mindfulness course could benefit the students and make their pharmacy program less stressful and more enjoyable. 


\subsubsection{Healthcare Professionals}

Health care professionals face a multitude of challenges on a daily basis when it comes to their workload, long hours, and dealing with upper level administration. This continually leads to chronic stress, professional burnout, and poorer quality of life [70]. Over $40 \%$ of nurses suffer occupational burnout, $28 \%$ of physicians endure symptoms of burnout, and $60 \%$ of psychologists acknowledge to being so distressed that they feel clinically ineffective [71-73]. Burnout can also lead to fatigue, insomnia, obesity, depression, premature aging, and hypertension [74, 75]. Burnout is becoming such a problem that it has created a call for action for health professionals to engage more in practices such as mindfulness. Mindfulness-based meditation has been suggested to better improve the lives of healthcare professionals and improve patient satisfaction.

Any healthcare profession (such as medicine, nursing, pharmacy, optometry, dentistry and psychology) is taxing and stressful. Between regular and clinical duties there are often times that a person is too busy (or too tired) to interact with friends and family, leading to a lack of social support. Moreover, physicians often put the needs of their patient first before their own. A research found that residents facing burnout were more likely to report that their own personal needs were 'inconsequential [76, 77]. In addition, another study reported that medical residents put professional achievements before familial, social, mental, and financial needs [78]. Competition in the healthcare field is so high that clinicians feel they are not successful, leading to overwork, stress, and fatigue. Wellness and self- prioritization are not advocated for enough when talking about healthcare professions. There should be programs or guidelines designed for physicians, pharmacist, nurses, etc. to take part in self-care and not face burnout from stress. A report found that physicians were more likely to engage in wellness programs, including mindfulness, when offered, reporting superior global well-being [79].

In order to combat stress among healthcare professionals, mindfulness has been suggested to ease symptoms of burnout. Mindfulness can help healthcare professionals become more "affectionate, compassionate, and friendlier," towards the patient. Practicing mindfulness-based stress reduction (MBSR) appears to improve well-being and dealing with pressure in these professionals [70]. One particular study taught participants different types of meditation practices, while incorporating more mindful tasks when eating, driving, walking, cleaning, and socializing with others. The ones that took part in this pre-post design quantitative research of MBSR obtained positive results for symptoms such as anxiety and depression, while showing an increase in empathy and spirituality [80].

Another mindful-based stress reduction study, specifically for nursing, resulted in significant increases in empathy after the completion of the study [56]. Simultaneously, nursing subjects on another MBSR program reported notable decreases on burnout and stress, while having increased levels of tranquility and life satisfaction [81]. Another uncontrolled study documented the effect of MBSR in psychology professionals; the participants indicated decreases of distress, negative thoughts, and anxiety, while increasing positive self-talk and self-compassion [53, 82]. They also reported better stress management and interpersonal functioning. The participants also stated that the mindfulness meditation activities improved their clinical training experience and made them more attentive and focused.

Although the findings for the clinical and non-clinical groups were promising, MBSR programs can have systematic issues. For example, the quantitative studies held small sample sizes and the 
practice time for meditation, whether at home or elsewhere, is very variable depending on the individual [70]. Also, there is no 'dose' that can be measured when it comes to mindful-based meditation, just the amount of mindfulness practice reported and expected results from it [70]. Lastly, not every healthcare professional may have enough time in their day to practice mindfulbased approaches due to heavy workloads, work attendance, and clinical rotations. Although there is supporting evidence that MBSR does lower stress, there are no physiological, neuro-hormonal, or cognitive measures that can act as markers [70]. Moreover, the majority of the studies recorded were self-reported results, with some providing physiological measures, such as salivary cortisol [70].

At the present, the suggestion is that perhaps the focus should shift towards behavioral variables, such as adherence, to evaluate the frequency and intensity of MBSR approaches. Observing methodologies with outcome research in conjunction with quantitative and qualitative variables can potentially show other meaningful data with both physical and psychological health outcomes [70]. More organized studies regarding mindful training should be followed in specific populations and also combined healthcare professionals.

\section{Conclusions}

Overall, it is believed that mindful-based stress reduction (MBSR) programs can help healthcare professionals manage stress, mental, physical, and emotional symptoms. It is important that professionals dedicated to psychotherapy, counseling, medicine, pharmacy, nursing and others have manageable stress levels, as they are around patients and their jobs require empathy and good bedside manners. Interpersonal relationships are what help clinicians connect with patients and mindful-based approaches can help them feel more connected with their patients, while being in a better state of mind.

Mindful-based meditation studies point mostly to positive effects on stress reduction as well as improvement of physical illnesses and mental health. However, the practice might not be favorable for everyone. A few studies have documented some negative results with mindfulness practice, and while it should be noted that these effects were rare, in some cases worsening effects of psychiatric symptoms, depression, anxiety, delusions of grandeur, euphoria, psychosis, and unusual behavior were observed $[83,84]$. Another important aspect is the instructor credentials to teach properly mindful-based practices. It is advisable for instructors to go through Kabat-Zinn's MBSR program for in-depth training over a certain number of years and commit to their daily, personal practice, but there are no studies addressing teacher training, which could in turn hinder mindful-based practice results [70].

In summary, practicing mindfulness has the potential to change one's life for the better. Mindfulness-based interventions can improve the cognitive, emotional, mental, and physical state of stressed-out undergraduate, graduate students and health-care professionals. These specific career paths are prone to high stress, burnout, fatigue, depression, and anxiety. Mindfulness-based practices should be incorporated into a daily curriculum via the school or medical based setting. By enlarge, there are proven data backing up these claims and mindfulness should be considered a top priority in higher education, faculty, and healthcare professionals. 


\section{Acknowledgments}

The manuscript was sponsored by the Underrepresented Women of Color Coalition (UR-WoCC) at the University of Houston.

\section{Author Contributions}

S. L. wrote the mini review and crafted the initial manuscript. S.L and M.V.T.S. revised the first draft. M.V.T.S finalized the manuscript and designed the tables.

\section{Competing Interests}

The authors declare that the manuscripts was conducted in the absence of any commercial or financial relationships that could be construed as a potential conflict of interest.

\section{References}

1. Kabat-Zinn J. Mindfulness-based interventions in context: Past, present, and future. Clin Psychol Sci Pract. 2003; 10: 144-156.

2. Mindful Staff. What is mindfulness [Internet]? Chicago: Mindful; 2020. Available from: https://www.mindful.org/what-is-mindfulness/.

3. Bakken EE. What is mindfulness [Internet]? Minneapolis: University of Minnesota; 2016. Available from: https://www.takingcharge.csh.umn.edu/what-mindfulness.

4. Batchelor M. Meditation and mindfulness. Contemp Buddhism. 2011; 12: 157-164.

5. Van Gordon W, Shonin E, Griffiths MD, Singh NN. There is only one mindfulness: Why science and Buddhism need to work together. Mindfulness. 2015; 6: 49-56.

6. Warren J, Farley. Mindfulness history and research [Internet]. Provo: My Best Self 101; 2019 [cited 2021 June 26th]. Available from: https://www.mybestself101.org/mindfulness-historyand-research.

7. Gethin R. Buddhist conceptualizations of mindfulness. In: Handbook of mindfulness: Theory, research, and practice. New York: The Guilford Press; 2015. pp.9-41.

8. Mikulas WL. Mindfulness: Significant common confusions. Mindfulness. 2011; 2: 1-7.

9. Kabat-Zinn J. An outpatient program in behavioral medicine for chronic pain patients based on the practice of mindfulness meditation: Theoretical considerations and preliminary results. Gen Hosp Psychiatry. 1982; 4: 33-47.

10. Shapiro S, Weisbaum E. History of mindfulness and psychology. In: Oxford research encyclopedia of psychology. Oxford: Oxford University Press; 2020.

11. Kang C, Whittingham K. Mindfulness: A dialogue between Buddhism and clinical psychology. Mindfulness. 2010; 1: 161-173.

12. Kabat-Zinn J. Full catastrophe living: Using the wisdom of your body and mind to face stress, pain, and illness. New York: Delacorte Press; 1990.

13. Germer CK, Siegel RD, Fulton PR. Mindfulness and psychotherapy. New York: The Guilford Press; 2005.

14. Shah S. Mindfulness Vs meditation [Internet]. Bengaluru: Art of Living; 2021. Available from: https://www.artofliving.org/us-en/blog/mindfulness-vs-meditation-know-both-well-and-pickthe-best-for-you. 
15. Tang YY, Hölzel BK, Posner MI. The neuroscience of mindfulness meditation. Nat Rev Neurosci. 2015; 16: 213-225.

16. Cabrera-Caban E, Garden R, White A, Reynoldson K. Mindfulness-based interventions: A brief review of their application to graduate student strain. Ind Organ Psychol. 2016; 53: 121-128.

17. Harris R. Acceptance and commitment therapy (ACT) introductory workshop [Internet]. Collingwood: Psychological Flexibility Pty Ltd.; 2007. Available from:

http://www.actmindfully.com.au/upimages/2007 Introductory ACT Workshop Handout Russ Harris.pdf.

18. Smith JA, Newman KM, Suttie J, Jazaieri H. The state of mindfulness science [Internet]. Berkeley: Greater Good magazine; 2017. Available from:

https://greatergood.berkeley.edu/article/item/the state of mindfulness science.

19. Hoffman $P$, Jefferies $E$, Ralph MA. Ventrolateral prefrontal cortex plays an executive regulation role in comprehension of abstract words: Convergent neuropsychological and repetitive TMS evidence. J Neurosci. 2010; 30: 15450-15456.

20. Goyal M, Singh S, Sibinga EM, Gould NF, Rowland-Seymour A, Sharma R, et al. Meditation programs for psychological stress and well-being: A systematic review and meta-analysis. JAMA Intern Med. 2014; 174: 357-368.

21. Speca M, Carlson LE, Goodey E, Angen M. A randomized, wait-list controlled clinical trial: The effect of a mindfulness meditation-based stress reduction program on mood and symptoms of stress in cancer outpatients. Psychosom Med. 2000; 62: 613-622.

22. Lerman R, Jarski R, Rea H, Gellish R, Vicini F. Improving symptoms and quality of life of female cancer survivors: A randomized controlled study. Ann Surg Oncol. 2012; 19: 373-378.

23. Carlson DE. Managing stress in critical illness: A question of balance. Crit Care Med. 2012; 40: 3327-3328.

24. DiRenzo D, Crespo-Bosque M, Gould N, Finan P, Nanavati J, Bingham CO. Systematic review and meta-analysis: Mindfulness-based interventions for rheumatoid arthritis. Curr Rheumatol Rep. 2018; 20: 75.

25. MacLean KA, Ferrer E, Aichele SR, Bridwell DA, Zanesco AP, Jacobs TL, et al. Intensive meditation training improves perceptual discrimination and sustained attention. Psychol Sci. 2010; 21: 829839.

26. Brewer JA, Worhunsky PD, Gray JR, Tang YY, Weber J, Kober H. Meditation experience is associated with differences in default mode network activity and connectivity. Proc Natl Acad Sci USA. 2011; 108: 20254-20259.

27. Kiken LG, Shook NJ. Looking up: Mindfulness increases positive judgments and reduces negativity bias. Soc Psychol Personal Sci. 2011; 2: 425-431.

28. Greenberg J, Reiner K, Meiran N. "Mind the trap": Mindfulness practice reduces cognitive rigidity. PloS One. 2012; 7: e36206.

29. Davidson RJ, Kabat-Zinn J, Schumacher J, Rosenkranz M, Muller D, Santorelli SF, et al. Alterations in brain and immune function produced by mindfulness meditation. Psychosom Med. 2003; 65: 564-570.

30. Chiesa A, Serretti A. Mindfulness-based stress reduction for stress management in healthy people: A review and meta-analysis. J Altern Complement Med. 2009; 15: 593-600. 
31. Basso JC, McHale A, Ende V, Oberlin DJ, Suzuki WA. Brief, daily meditation enhances attention, memory, mood, and emotional regulation in non-experienced meditators. Behav Brain Res. 2019; 356: 208-220.

32. Matousek RH, Dobkin PL, Pruessner J. Cortisol as a marker for improvement in mindfulnessbased stress reduction. Complement Ther Clin Pract. 2010; 16: 13-19.

33. Epel E, Daubenmier J, Moskowitz JT, Folkman S, Blackburn E. Can meditation slow rate of cellular aging? Cognitive stress, mindfulness, and telomeres. Ann N Y Acad Sci. 2009; 1172: 3453.

34. Jacobs TL, Epel ES, Lin J, Blackburn EH, Wolkowitz OM, Bridwell DA, et al. Intensive meditation training, immune cell telomerase activity, and psychological mediators.

Psychoneuroendocrinology. 2011; 36: 664-681.

35. Greenberg J, Romero VL, Elkin-Frankston S, Bezdek MA, Schumacher EH, Lazar SW. Reduced interference in working memory following mindfulness training is associated with increases in hippocampal volume. Brain Imaging Behav. 2019; 13: 366-376.

36. Braun M. Mindfulness and memory: The powerful link between mindfulness and learning [Internet]. New York: Psychology Today; 2019. Available from:

https://www.psychologytoday.com/us/blog/high-octane-brain/201906/mindfulness-andmemory.

37. Zenner C, Herrnleben-Kurz S, Walach H. Mindfulness-based interventions in schools-a systematic review and meta-analysis. Front Psychol. 2014; 5: 603.

38. Unsworth N, Heitz RP, Schrock JC, Engle RW. An automated version of the operation span task. Behav Res Methods. 2005; 37: 498-505.

39. Chambers R, Lo BC, Allen NB. The impact of intensive mindfulness training on attentional control, cognitive style, and affect. Cognit Ther Res. 2008; 32: 303-322.

40. Zeidan F, Johnson SK, Diamond BJ, David Z, Goolkasian P. Mindfulness meditation improves cognition: Evidence of brief mental training. Conscious Cogn. 2010; 19: 597-605.

41. Chan D, Woollacott M. Effects of level of meditation experience on attentional focus: Is the efficiency of executive or orientation networks improved? J Altern Complement Med. 2007; 13: 651-658.

42. Moore A, Malinowski P. Meditation, mindfulness and cognitive flexibility. Conscious Cogn. 2009; 18: 176-186.

43. Malinowski P. Neural mechanisms of attentional control in mindfulness meditation. Front Neurosci. 2013; 7: 8.

44. Colzato LS, Szapora A, Hommel B. Meditate to create: The impact of focused-attention and open-monitoring training on convergent and divergent thinking. Front Psychol. 2012; 3: 116.

45. Capurso V, Fabbro F, Crescentini C. Mindful creativity: The influence of mindfulness meditation on creative thinking. Front Psychol. 2014; 4: 1020.

46. Ding X, Tang YY, Tang R, Posner MI. Improving creativity performance by short-term meditation. Behav Brain Funct. 2014; 10: 9.

47. Torrance EP. The Torrance Tests of Creative thinking, verbal tests, forms A and B. New York: Personnel press; 1974.

48. Krowatschek D, Krowatschek G, Winger G. Marburger concentration training for adolescents. Dortmund: Borgmann Media; 2007. 
49. Wimmer L, Bellingrath S, von Stockhausen L. Cognitive effects of mindfulness training: Results of a pilot study based on a theory driven approach. Front Psychol. 2016; 7: 1037.

50. Levine GN, Lange RA, Bairey-Merz CN, Davidson RJ, Jamerson K, Mehta PK, et al. Meditation and cardiovascular risk reduction: A scientific statement from the American Heart Association. J Am Heart Assoc. 2017; 6: e002218.

51. Shah AJ, Ostfeld RJ. Attitudes of inner city patients with cardiovascular disease towards meditation. J Integr Cardiol. 2016; 2. Doi: 10.15761/JIC.1000152.

52. Powell PA. Individual differences in emotion regulation moderate the associations between empathy and affective distress. Motiv Emot. 2018; 42: 602-613.

53. Peterson LG, Pbert L. Effectiveness of a meditation-based stress reduction program in the treatment of anxiety disorders. Am J Psychiatry. 1992; 149: 936-943.

54. Shapiro S, Brown K, Astin J. Toward the integration of meditation into higher education: A review of research [Internet]. Florence: The Center for Contemplative Mind in Society; 2008. Available from: http://www.contemplativemind.org/files/MedandHigherEd.pdf.

55. Keogh E, Bond FW, Flaxman PE. Improving academic performance and mental health through a stress management intervention: Outcomes and mediators of change. Behav Res Ther. 2006; 44: 339-357.

56. Jain S, Shapiro SL, Swanick S, Roesch SC, Mills PJ, Bell I, et al. A randomized controlled trial of mindfulness meditation versus relaxation training: Effects on distress, positive states of mind, rumination, and distraction. Ann Behav Med. 2007; 33: 11-21.

57. El-Ghoroury NH, Galper DI, Sawaqdeh A, Bufka LF. Stress, coping, and barriers to wellness among psychology graduate students. Train Educ Prof Psychol. 2012; 6: 122-134.

58. Hyun JK, Quinn BC, Madon T, Lustig S. Graduate student mental health: Needs assessment and utilization of counseling services. J Coll Stud Dev. 2006; 47: 247-266.

59. Myers SB, Sweeney AC, Popick V, Wesley K, Bordfeld A, Fingerhut R. Self-care practices and perceived stress levels among psychology graduate students. Train Educ Prof Psychol. 2012; 6: 55-56.

60. Offstein EH, Larson MB, Mcneill AL, Mwale HM. Are we doing enough for today's graduate student? Int J Educ Manag. 2004; 18: 396-407.

61. Oswalt SB, Riddock CC. What to do about being overwhelmed: Graduate students, stress and university services. Coll Stud Dev. 2007; 27: 24-44.

62. Schure MB, Christopher J, Christopher S. Mind-body medicine and the art of self-care: Teaching mindfulness to counseling students through yoga, meditation, and qigong. J Couns Dev. 2008; 86: 47-56.

63. Sieja J. Mindfulness-based meditation and its effects on college students. Ypsilanti, MI: Eastern Michigan University; 2019.

64. Marshall LL, Allison A, Nykamp D, Lanke S. Perceived stress and quality of life among doctor of pharmacy students. Am J Pharm Educ. 2008; 72: 242-245.

65. Gallagher CT, Mehta AN, Selvan R, Mirza IB, Radia P, Bharadia NS, et al. Perceived stress levels among undergraduate pharmacy students in the UK. Curr Pharm Teach Learn. 2014; 6: 437-441.

66. Galante J, Dufour G, Vainre M, Wagner AP, Stochl J, Benton A, et al. A mindfulness-based intervention to increase resilience to stress in university students (the mindful student study): A pragmatic randomised controlled trial. Lancet Public Health. 2018; 3: e72-e81. 
67. Beck DL, Hackett MB, Srivastava R, McKim E, Rockwell B. Perceived level and sources of stress in university professional schools. J Nurs Educ. 1997; 36: 180-186.

68. Misra R, Castillo LG. Academic stress among college students: Comparison of American and international students. Int J Stress Manag. 2004; 11: 132-148.

69. O'Driscoll M, Byrne S, Byrne H, Lambert S, Sahm L. An online mindfulness-based intervention for undergraduate pharmacy students: Results of a mixed-methods feasibility study. Curr Pharm Teach Learn. 2019; 11: 858-875.

70. Irving JA, Dobkin PL, Park J. Cultivating mindfulness in health care professionals: A review of empirical studies of mindfulness-based stress reduction (MBSR). Complement Ther Clin Pract. 2009; 15: 61-66.

71. Bruce SM, Conaglen HM, Conaglen JV. Burnout in physicians: A case for peer-support. Intern Med J. 2005; 35: 272-278.

72. Pope KS, Tabachnick BG, Keith-Spiegel P. Ethics of practice: The beliefs and behaviors of psychologists as therapists. Am Psychol. 1987; 42: 993-1006.

73. Vahey DC, Aiken LH, Sloane DM, Clarke SP, Vargas D. Nurse burnout and patient satisfaction. Med Care. 2004; 42: II57-II66.

74. Miller KI, Stiff JB, Ellis BH. Communication and empathy as precursors to burnout among human service workers. Commun Monogr. 1988; 55: 250-265.

75. Spickard Jr A, Gabbe SG, Christensen JF. Mid-career burnout in generalist and specialist physicians. JAMA. 2002; 288: 1447-1450.

76. Miller NM, McGowen RK. The painful truth: Physicians are not invincible. South Med J. 2000; 93: 966-973.

77. Zoorob D, Shah S, La Saevig D, Murphy C, Aouthmany S, Brickman K. Insight into resident burnout, mental wellness, and coping mechanisms early in the COVID-19 pandemic. Plos One. 2021; 16: e0250104.

78. Ratanawongsa N, Wright SM, Carrese JA. Well-being in residency: A time for temporary imbalance? Med Educ. 2007; 41: 273-280.

79. Weiner EL, Swain GR, Wolf B, Gottlieb M. A qualitative study of physicians' own wellnesspromotion practices. West J Med. 2001; 174: 19-23.

80. Salmon P, Sephton S, Weissbecker I, Hoover K, Ulmer C, Studts JL. Mindfulness meditation in clinical practice. Cogn Behav Pract. 2004; 11: 434-446.

81. Mackenzie CS, Poulin PA, Seidman-Carlson R. A brief mindfulness-based stress reduction intervention for nurses and nurse aides. Appl Nurs Res. 2006; 19: 105-109.

82. Christopher JC, Christopher SE, Dunnagan T, Schure M. Teaching self-care through mindfulness practices: The application of yoga, meditation, and qigong to counselor training. J Humanist Psychol. 2006; 46: 494-509.

83. Bishop SR. What do we really know about mindfulness-based stress reduction? Psychosom Med. 2002; 64: 71-83.

84. Allen NB, Chambers R, Knight W, Blashki GB, Ciechomski L, Hassed C, et al. Mindfulness-based psychotherapies: A review of conceptual foundations, empirical evidence and practical considerations. Aust N Z J Psychiatry. 2006; 40: 285-294. 
OBM Integrative and Complementary Medicine 2022; 7(1), doi:10.21926/obm.icm.2201009

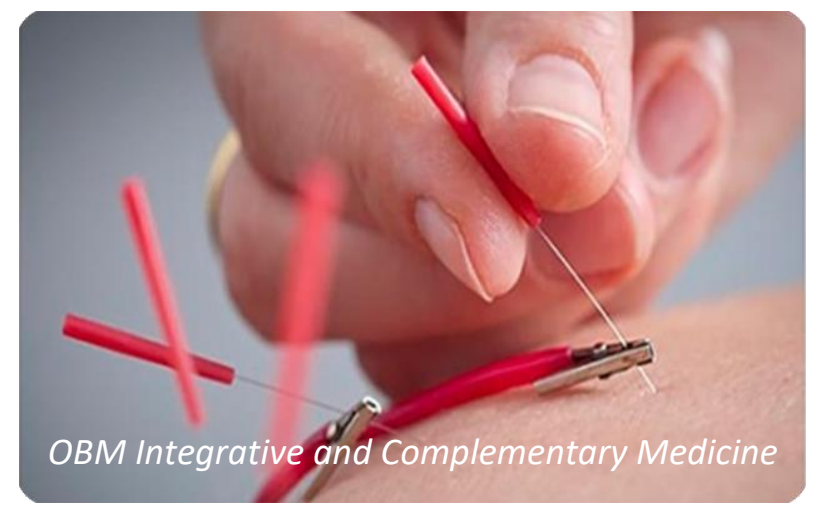

Enjoy OBM Integrative and Complementary Medicine by:

1. Submitting a manuscript

2. Joining in volunteer reviewer bank

3. Joining Editorial Board

4. Guest editing a special issue

For more details, please visit:

http://www.lidsen.com/journals/icm 